\title{
Uma nova forma de se fazer a guerra? Atuação das Empresas Militares de Segurança Privada contra o terrorismo no Iraque
}

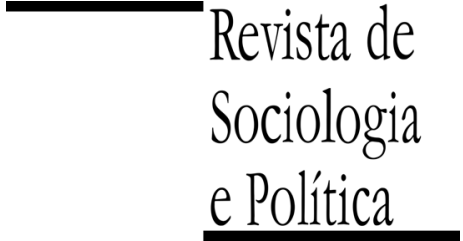

DOI 10.1590/1678-987315235303

\author{
Reginaldo Mattar Nasser e Tomaz Oliveira Paoliello
}

\begin{abstract}
Resumo
Os contratos de agências privadas com a Central de Inteligência Americana (CIA) e suas atividades de combate ao terrorismo, após os atentados de 11 de Setembro, foram um dos principais responsáveis pela expansão do mercado de segurança privada no Iraque. Este artigo pretende relacionar o papel crescente dos atores privados na estratégia de contraterrorismo da coalização liderada pelos EUA no contexto da ocupação do Iraque. Entendemos que falta de controle das atividades das empresas privadas de segurança tornam-se funcionais para as democracias liberais quando se envolvem nesse tipo de ação armada. Ou seja, um dos fatores responsáveis pela ascensão das Empresas Militares de Segurança Privada (PMSCs, na sigla em inglês) se relaciona à resposta a um ambiente em mudança operacional no terreno onde ocorrem as "novas guerras". O fato de o inimigo mais fraco poder ter influência sobre a coesão nacional das grandes potências, impondo custos políticos e econômicos significativos a seus adversários, faz com que a guerra seja travada além das operações militares no campo de batalha. Nossa hipótese é que os EUA, e a coalização militar que liderou a invasão do Iraque, procuraram gerenciar os riscos políticos (legitimidade) e os riscos de vida (para os combatentes e civis), considerados além daquilo que a opinião pública está disposta a aceitar. A estratégia revela-se num processo de transferência de risco para novas organizações civis de prestação de serviços, menos visíveis, de forma a tornar extremamente difícil imputar responsabilidades.
\end{abstract}

PALAVRAS-CHAVE: terrorismo; empresas privadas de segurança; Iraque; serviço de inteligência; EUA.

Recebido em 8 de Julho de 2014. Aprovado em 15 de Setembro de 2014.

\section{Introdução ${ }^{1}$}

\footnotetext{
${ }^{1} \mathrm{O}$ artigo faz parte do projeto de pesquisa "Paz Liberal ou Ocupação multilateral?", que foi financiado com recursos do CNPq. Agradecemos aos comentários elaborados pelos pareceristas anônimos da Revista de Sociologia e Política.

2 Sobre terminologia das empresas, ver a seção III.
}

\footnotetext{
3 O termo assimetria, em conflitos armados, refere-se a uma disparidade (militar ou econômica) entre as partes em confronto. Entretanto, os EUA adotam o termo "guerra assimétrica" para denotar uma tática militar (ou modo de operação) que explora as vulnerabilidades dos
}

Apesar de grande parte da literatura sobre o tema da privatização da segurança concentrar-se, principalmente, no apoio das Empresas Militares de Segurança Privada $(\mathrm{PMSCs})^{2}$ às operações militares dos EUA no Iraque e Afeganistão, julgamos que os impactos desse processo nas ações de contraterrorismo não tem tido o destaque merecido (Perry 2012). Aliás, na verdade, os contratos de agências privadas com a CIA e suas atividades de combate ao terrorismo, após os atentados de 11 de setembro de 2001, foram um dos principais responsáveis pela expansão do mercado de segurança privada no Iraque. Este artigo pretende explorar essa lacuna na literatura, relacionando o papel crescente de atores privados na estratégia de contraterrorismo da coalização militar liderada pelos EUA no contexto da ocupação do Iraque. Nosso objetivo é explorar o papel dos atores privados no cumprimento de fins estratégicos em contexto das chamadas guerras assimétricas ${ }^{3}$ indagando sobre quais seriam esses fins não explicitamente revelados.

Embora o papel dos PMSCs como atores internacionais de segurança seja, frequentemente, discutido a partir de uma perspectiva normativa, particularmente em relação à sua legitimidade, além do desafio que se coloca para sua regulamentação ser fundamental, entendemos que os problemas que envolvem seu controle tornam-se funcionais para as democracias liberais quando se envolvem nesse tipo de ação armada. Ou seja, um dos fatores responsáveis pela 
oponentes e enfatiza as diferenças em relação à tecnologia, armas e as regras de engajamento. Nesse sentido é que termos como terrorismo e insurgência são vistos como táticas empregadas em contexto de guerras assimétricas. ascensão dos PMSCs se relaciona às respostas às mudanças operacionais no terreno onde ocorrem as guerras assimétricas. Nesse sentido, examinaremos o papel das PMSCs no apoio a operações de contraterrorismo dos EUA no Iraque no contexto do projeto de reconstrução do pais (statebuilding) com destaque para as operações de inteligência.

O fato de o lado mais fraco poder influenciar a coesão nacional das grandes potências, impondo custos políticos e econômicos significativos a seus adversários, faz com que a guerra seja travada além das operações militares que ocorrem no campo de batalha. Nossa hipótese, baseada na argumentação de Shaw (2005) sobre o "modo ocidental de se fazer a guerra", é que os EUA e a coalizão militar que ele liderou na invasão do Iraque tiveram como objetivo o gerenciamento de riscos políticos (legitimidade) e os riscos de vida (para os combatentes e civis), que deveriam ser considerados além daquilo que a opinião pública estaria disposta a aceitar. Esse é um dos principais fatores que faz com que as grandes potências, baseadas nos princípios da liberal democracia, possam perder esse tipo de guerra. A estratégia revela-se num processo de transferência de risco para novas organizações civis de prestação de serviços, menos visíveis, de forma a tornar extremamente difícil imputar responsabilidades.

\section{O processo de ocupação militar no Iraque}

No dia $1^{\circ}$ de maio de 2003, o comandante em chefe das Forças Armadas dos Estados Unidos, presidente George W. Bush, declarou missão cumprida, após o fim das operações de combate que ocasionou a queda do governo iraquiano. A preparação para a remoção de Saddam Hussein, contida no plano OPLAN $1003 \mathrm{~V}$ (novembro de 2001), previa a existência de quatro fases: assegurar apoio internacional para o envio das tropas, moldar o campo de batalha, conduzir operações de combate e realizar operações militares limitadas após alcançar a derrota do regime iraquiano (Bensahel et al., 2008, p. 54). Pensando mais especificamente na última fase, isto é, na transição para um novo governo iraquiano, o presidente Bush emitiu Diretiva Presidencial de Segurança Nacional n. 24, em 20 de janeiro de 2003, que autorizava o Departamento de Defesa a assumir a responsabilidade administrativa do pós-guerra no Iraque (Dobbins et al., 2009). No dia 16 de abril de 2003, o comandante geral das forças da coligação anglo-americana no Iraque, general Tommy Franks, emitiu um comunicado anunciando a criação da Autoridade Provisória da Coalizão (CPA, na sigla em inglês), para exercer temporariamente poderes de governo (Feith 2008, p. 418).

A autoridade da CPA advinha, formalmente, do status dos EUA e da Grã-Bretanha qualificados como "poderes ocupantes" sob a égide das leis dos conflitos armados, tal como reconhecido na resolução do Conselho de Segurança da ONU (n. 1 483, de 22 de maio de 2003). De acordo com tal resolução, as autoridades designadas para esse fim teriam responsabilidades e obrigações em conformidade com o Direito Internacional aplicável aos Estados Unidos e Grã-Bretanha como potências ocupantes sob um comando unificado. A decisão de tratar o Iraque como um país conquistado liberou os EUA das restrições que normalmente estão associadas as operações de paz multilaterais sob mandato da ONU. Assim, muito embora o Conselho de Segurança da ONU não tenha endossado a intervenção militar no Iraque, acabou por reconhecer a autoridade norte-americana sobre o território iraquiano (Dobbins et al., 2009, pp. 12-13). O tradicional Direito Internacional de Ocupação foi amplamente substituído por uma nova modalidade de ocupação, no qual o multilateralismo serve como uma fonte alternativa de legitimidade. $\mathrm{O}$ ocupante tem enormes incentivos ao multilateralismo de ocupação por razões políticas, econômicas e de segurança. Ao mesmo tempo, o novo modelo, para ser bem sucedido, requer um amplo apoio 
internacional, que só pode ser obtido se houver cumprimento de certas exigências internacionais de autoridade partilhada e manifestação de respeito aos direitos humanos (Harris 2006).

Mas, apesar de não se enquadrar formalmente no escopo das Operações de Paz, a maioria das políticas concretizadas pela CPA foi consistente com as práticas estabelecidas nos padrões das missões de reconstrução posteriores ao conflito. Há de se levar em consideração que a estratégia da "luta global contra o terror", empreendida pelos EUA e aliados foi um dos fatores de maior impacto na configuração das operações de paz dentro do contexto internacional do período posterior à Guerra Fria. A partir de então ficou cada vez mais evidente a vinculação entre ações de combate ao terror e os processo de construção da paz no Iraque e Afeganistão. Nesse sentido, a linha de demarcação que foi apagada não é aquela que estabelecia os limites das ações de manutenção da paz (peacekeeping) e de imposição da paz (peace enforcement), mas sim entre a imposição da paz e da guerra contra o terror (Gowan \& Johnstone 2007, p. 9).

Além da incursão propriamente militar, uma outra mais discreta, mas com grande impacto no Iraque foi a entrada das PMSCs. O fato de os mais altos funcionários públicos norte-americano no Iraque, notadamente o enviado especial e chefe da CPA, Paul Bremer, bem como outros governos estrangeiros confiarem sua segurança às PMSCs era uma indicação do papel fundamental que essas empresas teriam no período pós-guerra. Não teriam como função apenas auxiliar o poder militar mas deveriam, sobretudo, dar suporte aos contratos de milhões de dólares para reconstruir a infraestrutura do país. No teatro de operações do Iraque, de acordo com relatório do Congressional Budget Office dos EUA, foram concedidos US $\$ 85$ bilhões em contratos privados para o período 2003-2007, compreendendo cerca de US\$ 76 bilhões para o Departamento de Defesa (DOD), US\$ 5 bilhões para a Agência dos Estados Unidos para o Desenvolvimento Internacional (USAID) e US\$ 4 bilhões para o Departamento de Estado. Essa tendência continuou em 2010, quando as PMSCs detinham cerca de $54 \%$ da força militar no Iraque e Afeganistão, ou seja, cerca de 250 mil contratados (Tonkin 2011, p. 34).

Conforme a presença norte-americana no Iraque passou a se voltar cada vez mais para a reconstrução do país, começou também a aumentar o número de seguranças privados envolvidos nesse tipo de atividade. A transformação de uma ação de invasão de um território para ocupação e, posteriormente, reconstrução, foi fundamental para a mudança do panorama da segurança no país. A reconstrução seria conduzida por diversas empresas estrangeiras, em sua maioria norte-americanas, que terceirizaram sua segurança por meio de outras empresas. Essa decisão foi tomada deliberadamente pelo comando da ocupação americana que, a partir de então, não poderia mais se responsabilizar diretamente pela segurança das atividades privadas no país. De acordo com Pelton (Pelton 2006, p. 105), foi uma estratégia passivo-agressiva de ocupação com a terceirização da segurança. Esse tipo de atividade é particularmente difícil de monitorar, principalmente se levarmos em consideração o grande número dos empregados de "terceiras nacionalidades", que se tornaram a principal força de trabalho no país. O trabalho de reconstrução no Iraque apresentou grandes possibilidades de investimentos, principalmente se considerarmos as potencialidades do mercado petrolífero. A quantidade de recursos aprovada pelo Congresso dos EUA para a reconstrução do Iraque era, em 2003, dez vezes maior do que foi destinado ao Afeganistão, US\$ 20 bilhões contra US\$ 2 bilhões; e em 2005 já era 25 vezes maior (ibidem). 


\section{Tipologia das empresas militares de segurança privada}

Há inúmeros termos e siglas utilizadas pelos estudiosos, tribunais e governos para se referirem à pessoa jurídica que estabelece contrato com agências governamentais ou empresas para fornecer equipamentos e/ou serviços em zonas de conflitos armados. Private Military Companies, Private Military Firms ou Private Military and Security Companies são termos que frequentemente são usados para descrever o fenômeno da privatização de questões relacionadas ao uso da violência indiretamente por instituições estatais. Por vezes, deparamo-nos com várias definições sobre o que seriam as empresas privadas que realizam missões militares e aquelas que cuidam de temas de segurança. De acordo com o Centro Democrático das Forças Armadas dos EUA (DCAF) (United States 2011), PMSCs são as empresas que oferecem serviços especializados relacionados às guerras e conflitos armados, incluindo operações de combate, planejamento estratégico, serviços de inteligência, suporte logístico e operacional e treinamento de pessoal (Schreier \& Caparini 2005).

Muitas vezes os termos, contractor, military contractor, private contractor, ou mesmo alguma combinação destes, como private military contractor são usados para descrever tanto a entidade corporativa como o indivíduo contratado. De acordo com a definição do documento do Departamento de Defesa AR 715-9 (DCAF 2006), contractor é um cidadão empregado por uma companhia militar privada que foi contratada pelo governo para apoiar ou aprimorar as agências governamentais em operações de combate.

Diversos autores buscaram classificar e diferenciar as empresas militares e de segurança privadas umas das outras. Esse esforço resultou em diferentes "taxonomias" para as empresas. Singer (2008), um dos mais importantes analistas do tema, tenta classificar as empresas em três tipos diferentes de acordo com os serviços prestados. O primeiro tipo, as "provedoras militares" (military provider firm), atuam no ambiente tático, nos combates propriamente ditos. Os empregados dessas empresas estarão diretamente envolvidos em combate, como forças especiais ou como comandantes. Esse tipo de função talvez seja a mais parecida com o que costumava se chamar mercenário, combatentes contratados atuando diretamente em prol de um dos lados do conflito armado (idem, p. 92)

O segundo tipo, as "consultoras militares" (military consultant firm), atuam no treinamento e aconselhamento das forças do cliente. Esse tipo de empresa não se envolve diretamente no combate, ao contrário das chamadas "fornecedoras militares", no entanto estão intimamente ligadas à forma de atuação das forças de combate para a qual trabalham. Apesar disso, seu papel pode ser muito ativo no panorama geral do conflito. Embora, provavelmente, não vá se envolver diretamente em combate, a transformação que pode operar nas forças que esteja treinando ou aconselhando pode mudar a forma de agir das tropas. Além de ter influência na estratégia adotada, estão muitas vezes ligadas à reestruturação de Forças Armadas de Estados considerados falidos, e tem papel fundamental na forma em que essas novas forças serão organizadas (idem, pp. 95-97).

O terceiro tipo são as "empresas de apoio militar" (military support firm), que atuam nas atividades de logística, transporte, inteligência, apoio técnico e suprimento. Esse tipo de empresa tem se mostrado cada vez mais comum com a reestruturação das Forças Armadas dos países ocidentais, principalmente Reino Unido e Estados Unidos. Grande parte da logística das Forças Armadas norteamericanas foi terceirizada, a partir de meados dos anos 1980, quando foram criados os primeiros contratos nesse sentido (Schwartz 2010).

Antes do esforço de classificação de Singer, já havia diversas tentativas de definir as PMSCs. A mais comum divide as empresas entre ativas e passivas, 
classificação usada por alguns analistas, mas principalmente pela própria indústria da segurança. As chamadas "ativas" são empresas que se engajam diretamente nos combates. As "passivas" são empresas que fornecem treinamento ou que trabalham na proteção de instalações e território. O problema com essa forma de classificação é que os resultados da ação de uma empresa passiva podem ir além de suas atribuições iniciais. A decisão de contratar uma empresa "passiva", que não busque o engajamento com o inimigo pode, da mesma forma, ter grande efeito estratégico (Singer 2008, p. 89). Por exemplo, uma empresa dedicada a proteger uma área pode estar preservando um ponto estratégico da guerra e, nesse sentido, tornar-se um alvo importante para o inimigo. As próprias empresas buscaram esse tipo de definição para legitimar sua atividade, já que essa divisão apresenta um claro aspecto normativo. A maioria das empresas se caracteriza como passivas em contraponto a empresas ativas/agressivas, que seriam mais facilmente caracterizadas como mercenárias, e que poderiam influir diretamente no desfecho do conflito.

Outra tipificação comum, relacionada à descrita anteriormente, separa "empresas militares privadas" de "empresas de segurança privada". O problema é que há diversas firmas que se definem como empresas de segurança, mas "desempenham funções militares, com consequências militares" (idem, p. 90). Embora seja possível defender a existência, de fato, de uma divisão entre as atividades de policiamento e segurança pública e as atividades militares, o uso que as empresas passaram a fazer dessa forma de classificação acabou tornando os conceitos vazios. De acordo com Singer, o limite entre elas é mais fácil de ser percebido em Estados "robustos" como os EUA, mas é muito mais difícil de ser definido em Estados fragilizados, onde o ordenamento interno convive com o conflito militar (idem, p. 73)

De acordo com Abrahamsen e Williams (2011), uma exaustiva e completa distinção entre empresas de segurança privada e as que exercem atividades militares, além de ser imprecisa, revela-se inútil. Por vezes, estão baseadas na falsa suposição de que apenas as atividades militares internacionais são preocupações relevantes no campo da segurança internacional, deixando o restante para os estudos na área de segurança pública ou de criminologia (idem, p. 35). No caso do conflito no Iraque podemos perceber, com clareza, o problema gerado por esse tipo de classificação. A Blackwater ${ }^{4}$, empresa de segurança atuante no Iraque, que empregou antigos membros das forças especiais norteamericanas, contratada por outras empresas, por Organizações Não-Governamentais (ONGs) e pelo governo norte-americano para proteger instalações, comboios e pessoas importantes, por diversas vezes teve seus homens envolvidos em combate direto contra insurgentes. Seria então, dependendo da situação, uma "empresa militar" e não uma "empresa de segurança". Portanto, como definir se o papel dos funcionários de uma empresa que atua em uma zona de conflito é "proteger ou combater" (Uesseler 2008)?

A tipificação de Singer, em contraposição à tipificação enviesada defendida pela própria indústria, é baseada em conceitos militares, e classifica as empresas de acordo com sua proximidade ou distância das linhas de frente do combate. Esse tipo de diferenciação ainda está claramente ligada à atividade exercida por cada empresa, apesar de não tentar atribuir um caráter normativo a essa classificação. O problema que continua presente na tentativa de Singer em classificar as empresas é que o caráter de suas atividades pode mudar de caso a caso, e estas podem exercer funções diferentes mesmo dentro de um mesmo contexto. De certa forma é o mesmo problema exposto pelo exemplo da Blackwater. Cada operação exigiria um exame aprofundado da forma pela qual se dá a inserção da empresa. Apesar de suas limitações, esse tipo de classificação pode ser útil para observarmos a forma como as empresas se inserem no mercado militar e o amplo escopo de suas atividades. 
Os limites entre cada uma das funções elencadas por Singer, podem, muitas vezes, ser tênues, sendo que diversas empresas transitam entre essas formas de atuação de acordo com as circunstâncias. A própria Blackwater forneceu seguranças no Iraque e no Afeganistão, mas possui bases de treinamento em solo norte-americano para a formação de soldados e forças de segurança internacionais (Scahill 2008). Para Avant (2005, p. 17), que adota a divisão formulada por Singer, as empresas em si não deveriam ser classificadas por esses tipos, mas sim pelos contratos assinados em cada caso. De acordo com a autora, a flexibilidade das empresas exige que analisemos a função de cada uma delas caso a caso, já que uma mesma empresa pode, em um contrato, fornecer treinamento e, em outro, apoio logístico. Talvez essa tipificação de empresas seja mais relevante para revelar a ampla gama de funções hoje cobertas pelas PMSCs, do que nos ajudar a enquadrar seu funcionamento. Singer fornece pistas sobre os diferentes tipos de função que uma empresa militar pode oferecer, mas corre-se o risco de não perceber a flexibilidade de ação das mesmas empresas.

Percy (2007) propõe uma tipificação, decorrente da formulada por Singer, mas com um sentido diverso, pois considera principalmente a evolução histórica dos serviços militares privados. Ela está menos preocupada em estabelecer com minúcia o tipo de operação de cada empresa do que em estabelecer uma diferença entre as empresas atuais e as empresas do primeiro tipo definido por Singer. Para a autora existem três tipos de provedores de serviços militares em perspectiva histórica: os mercenários, as empresas militares privadas "combatentes" e as empresas militares privadas de segurança ou "não combatentes". As empresas combatentes de Percy equivalem às empresas provedoras militares de Singer, que fornecem o serviço militar propriamente dito, substituindo ou complementando as forças de combate de um dos lados envolvidos no conflito.

Atualmente, não existe nenhuma empresa desse tipo oferecendo abertamente seus serviços no mercado militar privado. Para a autora, portanto, é preciso levar em consideração o contexto de existência dessas empresas e separá-las do tipo de empresa existente atualmente. A formulação da autora também decorre das tipificações normativas elencadas anteriormente, e de certa forma, confirma o sucesso das diversas empresas em se dissociar das antigas "empresas combatentes". A percepção de que as empresas sejam estruturas corporativas, controladas pelo mercado, alinha-se de maneira crucial com a ideologia liberal que ajuda, por sua vez, sua construção de legitimidade (Dunigan 2011, p. 18). A compreensão de Avant (2005) parece ser mais abrangente e incorpora mais casos distintos. Além de usar o modelo de Singer, ela transporta esse modelo para empresas que agem em serviços de policiamento e manutenção da ordem interna.

Nesse sentido, empresas que prestam serviços de policiamento armado, como a $S D S$ no México ou a Blackwater no Iraque, são incluídas no primeiro tipo de empresa (as que enfrentam diretamente as ameaças), mas em um eixo distinto, o do policiamento e ordenamento interno. O mesmo poderia ser dito, por exemplo, de empresas que fornecem serviços de treinamento. A norteamericana $M P R I$ treinou as tropas croatas, enquanto que outra empresa norteamericana, a DynCorp ficou encarregada do treinamento da polícia iraquiana. Nesse caso, as duas seriam consideradas empresas do segundo tipo, que fornecem consultoria, mas em eixos distintos, a primeiro no eixo militar, e a segundo no eixo do policiamento (Dunigan 2011, pp. 16-22). A autora também contribui para a compreensão do papel das empresas ao defender a consideração de suas funções por contrato e pelo contexto. Isso nos ajuda a compreender o fato de que uma mesma empresa possa prestar diferentes tipos de serviço, ou até que um mesmo contrato mude de caráter dependendo das circunstâncias. A $D S L$, que fornece serviços de vigilância e guarda de instalações, funções primor- 
dialmente de policiamento, enfrentou insurgentes diretamente na Colômbia, aproximando-se de uma empresa militar "combatente" (idem, p. 170). O conceito de "empresa de segurança privada" da autora (private security company) engloba todas essas nuances e diferenças em um mesmo fenômeno. A denominação consagrada utilizada por Percy, é a de "private military and security company" ou empresa militar e de segurança privada (PMSC), e será a denominação que adotaremos no presente texto.

Kinsey (2006) parte da mesma compreensão de Avant em privilegiar os casos específicos, em vez de tentar classificar as empresas de forma genérica. Para o autor existem dois critérios a serem levados em consideração: o "objeto a ser protegido" e os "meios para proteger o objeto". Os objetos são classificados dentro de um contínuo entre público e privado, e os meios estão num contínuo entre meios letais e não letais. (Dunigan 2011, pp. 13-14) As chamadas empresas "provedoras" de Singer seriam prestadoras dos meios letais, e podem prestar segurança tanto para objetos públicos quanto privados. O caso do Iraque é crucial para compreendermos que uma mesma empresa pode estar envolvida tanto na proteção de bens públicos como privados, mas todos fazendo parte da mesma operação. Já as empresas "consultoras" e de "apoio" normalmente fornecem serviços de tipo não letal, como vigilância, treinamento e monitoramento, tanto na dimensão pública quanto privada, ou seja, podem, por exemplo, treinar policiais ou treinar funcionários de uma terceira empresa. Essa classificação é interessante principalmente por nos revelar também a ampla gama de clientes que passam a se beneficiar dos serviços das empresas.

\section{Terceirização dos serviços de inteligência}

O crescimento das empresas privadas ocorreu para além das áreas de proteção de bens e pessoas e de treinamento de forças policiais e Forças Armadas que acabamos de discutir. A privatização de serviços de espionagem talvez seja a fronteira mais avançada no processo de privatização de funções tradicionalmente reservadas ao Estado, sendo que, nos últimos anos, nota-se um aumento notável da privatização de funções de informação, monitoramento e inteligência. O processo passou a ter grande repercussão, em 2007, quando o jornalista Tim Shorrock (Shorrock 2007) obteve dados que revelaram os gastos das agências de inteligência do governo dos EUA com contratos privados, o que estimulou uma série de outros investigadores a abordar o tema, ainda que seja bastante difícil a obtenção de dados.

Conforme revela Mazzetti (2010) as Forças Armadas dos EUA não tinham condições de organizar operações no Afeganistão sem as informações de uma rede de inteligência totalmente privatizada, seja por falta de pessoal disponível e capacitado, seja por impedimentos legais. De acordo com o jornalista, que conduziu entrevistas com uma série de oficiais que operavam no Afeganistão, havia falta de informações provenientes das fontes governamentais, das agências norte-americanas ou paquistanesas que colaboraram com os EUA, sobre os grupos combatentes no país e no Paquistão. A solução foi ampliar as fontes de informação privadas.

A operação adquiriu caráter secreto, pois de acordo com as regras do Pentágono as Forças Armadas são impedidas de realizar contratação de espionagem privada. As informações provenientes do Paquistão, consideradas essenciais para a realização de operações no país vizinho, são também quase exclusivamente baseadas nessa rede privada, já que militares norte-americanos não podem atuar no país. A autorização que consta no contrato com as empresas seria apenas para coletar "informações atmosféricas" e dados sobre as estruturas tribais no Afeganistão e Paquistão. No entanto, de acordo com Mazzetti (idem), quase que diariamente a rede de espionagem privada repassa dados 
sobre os movimentos dos grupos insurgentes para os altos escalões das Forças Armadas norte-americanas. O limite tênue entre informações atmosféricas e espionagem é apenas um exemplo de como contratos privados são usados para evitar os diversos impedimentos legais (idem). Por meio da Agência de Inteligência do Departamento de Defesa, o governo dos EUA revelou que $70 \%$ do orçamento confidencial de inteligência é gasto em contratos privados (Shorrock 2007). O valor que era de US\$ 18 bilhões, em 1995, passou para US\$ 48 bilhões em 2005. É evidente o crescimento desse tipo de atividade relacionada à questão do terrorismo, dado que o grande aumento dos gastos em contratos privados ocorre a partir de 2001. Estima-se que $90 \%$ dos contratos de inteligência são confidenciais, e aproximadamente $60 \%$ do pessoal da CIA é terceirizado (idem).

A empresa L-3 Communications é um caso importante para que possamos compreender a dimensão do fenômeno. Desde sua fundação, em 1997, a companhia tem uma política agressiva de aquisição de diversas empresas nas áreas de aviação, comunicação, inteligência, vigilância e reconhecimento. A empresa controla, por exemplo, a Titan Corp, uma das maiores prestadoras de serviços de tradução para as forças norte-americanas que operam no Iraque. Estima-se que as missões militares ou de inteligência de campo no Iraque contem com a presença de, pelo menos, um tradutor terceirizado (Chatterjee 2006). Como veremos adiante, esses tradutores foram implicados em denúncias de tortura juntamente com agentes de inteligência e guardas prisionais na prisão de Abu Ghraib.

A L-3 Communication e suas subsidiárias são também uma das maiores fabricantes de drones (veículos aéreos não tripulados), para as Forças Armadas norte-americanas. Os drones são utilizados no Iraque para bombardeios, mas principalmente para vigilância, inteligência e levantamentos de informações sobre áreas de combate. Uma série de subsidiárias da L-3 prestam uma gama de serviços ligados aos veículos não-tripulados, como manutenção, equipamento, operação (pilotagem) e, finalmente, sistematização e análise das informações captadas. Estima-se que seria impossível às Forças Armadas norte-americanas manter e operar suas aeronaves não-tripuladas sem a contratação de empresas que prestem uma série de serviços articulados com sua operação (idem). Os drones tornaram-se um elemento fundamental para missões de monitoramento e de bombardeio dos insurgentes em terrenos de difícil acesso. Não é por acaso que, na mesma medida em que crescem os casos de missões de reconhecimento por meio dos veículos não tripulados, crescem também a quantidade de ataques feitos por esse mesmo veículo. Relatório do Congresso dos Estados Unidos revelou que todas as coordenadas enviadas aos centros que planejam e operam os bombardeios são fornecidas por empresas terceirizadas. Embora diversas operações já estejam inteiramente nas mãos de empresas terceirizadas, mesmo nos casos em que as operações de bombardeio são conduzidas pelas Forças Armadas, os alvos dos bombardeios são selecionados por essas empresas (United States 2008, p. 22).

Causou espanto, durante o escândalo Snowden, a informação de que trabalhava para o governo norte-americano, por meio de um subcontrato com a empresa Booz Allen Hamilton, a responsável por sistematizar os dados obtidos por meio de violações de sigilo de conteúdos de telefones e e-mails (King 2014). Essa é apenas uma de muitas empresas que avançaram no ramo de recolhimento de dados de inteligência. No Iraque, a empresa MacB, subsidiária da gigante Lockheed Martin, oferece serviços de análise de documentos apreendidos e apoio para operações de contrainsurgência e contraterrorismo, usando sua extensa rede de contatos, incluindo antigos membros do regime de Saddam Hussein, e das diferentes facções insurgentes (Pincus 2007). 
${ }^{5}$ No caso reportado, as redes privadas de informantes são formadas por ex-membros da CIA afastados por envolvimento em escândalos e ações ilegais.
Outro importante protagonista da inteligência privada no Iraque é, novamente, a L-3 Communications e suas diversas subsidiárias (Chatterjee 2006). A GSI faz parte do grupo L-3 e recebeu, em 2004, um dos maiores contratos para operações de inteligência no Iraque (L-3 Communication's Government Services... 2005). Homens e equipamento da empresa se espalharam pelo país em operações que vão desde a instalação de grampos telefônicos, monitoramento de e-mails até agentes infiltrados para recolhimento de informações. De acordo com Mazzetti (2011), o Pentágono tem se valido, cada vez mais, de fontes de inteligência privada, inclusive para planejar operações militares, desvinculando-se dos controles governamentais de Washington ou mesmo da própria CIA ${ }^{5}$. Os vínculos com as empresas privadas variam desde contratos firmados em concorrências abertas até relatórios preparados com financiamento privado, enviados aos chefes de operações no Departamento de Defesa (idem).

O movimento de privatização da inteligência cria uma relação complexa com as agências estatais já que a influência dos serviços de inteligência e monitoramento não fica necessariamente restrita à dimensão tática, mas pode, no limite, influenciar a construção dos objetivos estratégicos traçados pelas Forças Armadas. Diretores da CIA declararam que seus agentes no Iraque são chefiados por agentes privados, que selecionam quando e como devem ir a campo, e informam quais serão os alvos. Ora, se a dependência é de fato tão profunda como as referências analisadas nos mostram, a empresa que presta serviços de informação age não apenas como fornecedora da inteligência, mas também como filtro para as informações que chegam aos centros de tomada de decisões. Para ter-se ideia da capacidade de selecionar e controlar informação das empresas privadas, basta mencionar que todos os cruzamentos de dados entre as diferentes agências de inteligência são feitos por softwares desenvolvidos, mantidos e operados por empresas terceirizadas (Shorrock 2007). Em outras palavras, as empresas têm poder de selecionar as informações que são qualificadas como mais relevantes, além de estabelecerem a hierarquia de dados mais ou menos importantes para as futuras decisões (Leander 2005).

\section{Interrogatórios e sistema prisional}

As empresas militares de segurança privada tiveram participação relevante relacionada a uma série de relatos de violência por meio da prática de tortura e assassinatos de prisioneiros nas prisões iraquianas. Funcionários terceirizados, trabalhando em equipes junto aos funcionários do Departamento de Defesa ou das agências de inteligência, como a CIA, exerceram várias tarefas, como tradução durante os interrogatórios, consultoria sobre informações e inteligência sobre os prisioneiros e grupos insurgentes, ou ainda consultoria a respeito das técnicas de interrogatório e tortura. Os escândalos de violação de direitos humanos na prisão de Abu Ghraib, em Bagdá, foram alguns dos casos mais importantes envolvendo a participação de contratados privados em práticas ilegais. Na prisão, os funcionários da empresa Titan, por exemplo, eram responsáveis por prestar serviços de tradução e interpretação, enquanto que os funcionários da empresa CACI eram interrogadores terceirizados (Tonkin 2011, p. 24).

Os primeiros casos de violações, ocorridos no ano de 2003, só passaram a ser investigados e ganhar maior repercussão em 2005, quando o jornal Washington Post passou a divulgar relatos dos chamados "ghost detainees", prisioneiros detidos sem registro de entrada em instalações do governo norte-americano, sem serem submetidos a qualquer processo legal. Além dos relatos de prisões ilegais em instalações oficiais, como a prisão de Abu Ghraib, existem também denúncias de prisões semelhantes em locais não registrados em diversas partes do mundo (White 2005). Os registros dos interrogatórios conhecidos 
${ }^{6}$ A Titan Corp foi posteriormente adquirida pela empresa L3 Communications. demonstram a participação constante de contratados de empresas privadas. De acordo com Avant (2005, p. 22) apesar da maioria dos empregados terceirizados estarem "contratados em cargos de apoio operacional e segurança interna, tiveram papel central no combate à insurgência iraquiana”.

O primeiro caso de violações em interrogatórios de grande repercussão ocorreu em 2003, na prisão de Abu Ghraib. Um prisioneiro, sob custódia da CIA, supostamente relacionado a atentados com bomba, foi morto durante interrogatório após ser submetido à tortura. O prisioneiro foi encontrado numa posição chamada pelos torturadores de "palestinian hang", em referência às práticas utilizadas por israelenses contra prisioneiros palestinos. A causa da morte, classificada como homicídio, foi registrada como asfixia, devido ao uso de um saco plástico no rosto do prisioneiro (Hettena 2005). A investigação concluiu que os dois responsáveis pela sessão de tortura que resultou na morte do prisioneiro eram um agente da CIA, Steve Stormoen, e um contratado privado. O caso só começou a ser julgado como crime de guerra oito anos depois, em 2011, e apenas Stormoen foi investigado. Na maioria das notícias e artigos relacionados ao caso, o nome do funcionário terceirizado sequer era mencionado (Apuzzo \& Goldman 2011). O contratado privado não foi indiciado, pois recebeu imunidade qualificada. Isto se refere a quando um funcionário agindo em nome do governo federal não pode ser judicialmente responsabilizado por violar os direitos de terceiros. No período entre as denúncias e o julgamento, Stormoen se afastou da agência de inteligência e ingressou no mercado privado, contratado pela empresa SpecTal, especializada em ações de inteligência e contraterrorismo, cujo principal cliente é o governo dos EUA (CIA Officer May Face War 2011; Bloomberg 2014).

O mecanismo por meio do qual funcionários do governo, afastados por violações, retornam como contratados terceirizados parece ser bastante frequente, já que muitas empresas não verificam registros criminais pregressos de seus novos funcionários. Desse modo, esse mecanismo permite que os mesmos funcionários envolvidos em violações retornem ao trabalho junto ao Departamento de Defesa dos Estados Unidos ainda que tenham sido demitidos, ou que sua empresa anterior tenha perdido o contrato (Dunigan 2011; Avant 2005). Em 2004, um grupo de 256 iraquianos, ex-prisioneiros de Abu Ghraib, entraram com um processo nos Estados Unidos contra as empresas CACI International e Titan Corp ${ }^{6}$, as duas empresas contratadas pelo governo norte-americano para prestar serviços de interrogatório e tradução nas prisões iraquianas. Apesar de diversos funcionários do Departamento de Defesa terem sido indiciados nos casos de abusos nas prisões, nenhum contratado privado foi processado, ainda que estivessem comprovadamente envolvidos, no mínimo, em 36\% dos casos de abuso na prisão de Abu Ghraib. Dentre os crimes relacionados às empresas estão estupros, abuso de autoridade, violência extrema e assassinato, incluindo vítimas menores de idade (Borger 2004).

Nos casos de violações cometidas por contratados privados, fora dos Estados Unidos, principalmente em zonas de guerra, os acusados contam com um duplo escudo de proteção e servem, exatamente por isso, também como escudos para o próprio exército e demais agências do governo note-americano, como a CIA. As cortes estaduais que julgaram as empresas denunciadas pelos prisioneiros iraquianos acabaram por descartar o julgamento dos funcionários e suas empresas. De acordo com a jurista Kathryn Johnson, é possível verificar uma racionalidade, nas Cortes, de impedir que ações realizadas em zonas de guerra fossem examinadas e julgadas nos tribunais civis (Johnson 2012, p. 1421). Nas defesas dos contratados privados aparecem dois dispositivos que os protegem de julgamento. Em primeiro lugar, nos casos expostos, a lei federal precede as leis estaduais, geralmente mais severas. Dessa maneira, os acusados não podem ser julgados nem nas cortes de seus estados de origem, nem naqueles onde estão 
instaladas as empresas. Além de dificultar a ação das vítimas, que já sofrem pela falta de meios para abrir um processo em outro país, isso abre a possibilidade de que os réus utilizem a "imunidade soberana", prevista para funcionários do Estado, mas estendida para contratados privados das mesmas agências. A imunidade prevê que as reivindicações de delito são desconsideradas em face de "importantes interesses federais" (idem, p. 1 426). Dessa maneira os contratados privados e as empresas que os contratam ficam blindados por violações e desvios de conduta que possam ter cometido nas zonas de guerra. Esse dispositivo favorece significativamente as operações de combate ao terrorismo no Iraque, pois permite que funcionários privados utilizem de procedimentos que estejam fora do alcance dos funcionários públicos sem ter de passar necessariamente por escrutínio público.

\section{Regulação das Empresas Militares de Segurança Privada}

O crescimento exponencial das atividades das PMSCs e, principalmente, o impacto de suas operações na imprensa, passaram a estimular debates a respeito da forma pela qual seria possível regulamentar suas atividades. O ponto de partida da regulação se dá em torno da percepção, já relatada, de que as empresas operariam numa espécie de vácuo jurídico, aproveitando-se dos limites pouco nítidos entre as esferas pública e privada, bem como entre o nacional e o internacional. Apesar da grande quantidade de artigos e livros críticos ao processo de terceirização das funções de segurança, é muito difícil encontrar ideias que sejam divergentes do ideário neoliberal que serve como base ideológica para a expansão da privatização. O resultado dessa influência é um quase consenso entre especialistas no tema (Avant 2005; Singer 2008) sobre a necessidade de formular maneiras de regular a atividade das empresas militares de segurança privada sem, contudo, negar a necessidade de sua existência. Fontes distintas de regulação ocorrem em diversas frentes: formais, como pela ONU ou legislações específicas de cada Estado; modos híbridos de administração, com acordos firmados entre grupos de Estados e empresas, e entidades privadas, como associações de indústria e códigos de conduta (RichemondBarak 2011, p. 1 028), além do suposto "controle pelo mercado".

Como veremos, a percepção da necessidade de regulação parte de uma suposição "pragmática" de que seria impossível proibir tais atividades dado o estágio avançado de dependência de diversos governos, empresas e organizações internacionais das PMSCs. No entanto, os autores deixam de mencionar que a regulação e o enquadramento jurídico das empresas, evidentemente, significará a formação de um marco regulatório que, mais do que legalizar, deverá legitimar suas operações.

Entendemos que Moore (2011) resume bem o argumento liberal que apoia a regulação das atividades das empresas que atuam em funções militares. A autora observa que defesa e segurança são as únicas áreas em que o controle público deve ser mais desejável do que o controle privado descentralizado. Entretanto, isso não significa, nas palavras da autora, que o mercado não possa prover serviços mais baratos e eficientes, como é o caso de todas as demais áreas da economia. Esse aparente paradoxo se resolveria com uma eficiente regulação do mercado de segurança pelo Estado, de maneira que os interesses privados não interfeririam nos interesses públicos. O Estado é um instrumento de regulação privilegiado já que, ao menos no caso dos Estados Unidos, é também o maior cliente dessas empresas. A primeira e mais eficiente maneira de regular as atividades das empresas seria, então, o próprio mercado. A chamada "regulação de mercado" pressupõe que a própria concorrência entre empresas cuidaria de selecionar e premiar as que forem mais eficientes e que cometerem menos desvios e infrações. Ou seja, as empresas que tiverem melhor 
custo/benefício, e que atuem dentro das regras estabelecidas, irão prosperar. O Estado, como grande cliente, seria um regulador apenas pelo fato de premiar ou punir as empresas com grandes contratos.

A ideia de "seleção natural" faz parte, de alguma forma, da maioria dos sistemas regulatórios que serão discutidos. No entanto, Moore (idem) enumera quais seriam as características específicas do mercado de segurança que impedem que esse mecanismo funcione de maneira eficiente. Em primeiro lugar, existe grande déficit de transparência nos contratos firmados entre o governo e as empresas de segurança privada. No caso dos contratos assinados pelo governo norte-americano com empresas de segurança, em 2001, 79\% dos contratos foi firmado por concorrência aberta. Em 2005 o número havia caído para $48 \%$. Isso significa que a falta de transparência só tendeu a se agravar, de maneira que fica difícil avaliar quais os critérios utilizados para contratação de mais da metade das empresas. A autora alerta para a correlação entre as grandes quantias despendidas em lobby junto ao governo e os vencedores dos principais contratos. Existe uma coincidência entre os grandes "doadores" e grandes beneficiários de contratos assinado pelo governo. Por último, menciona o movimento de "porta giratória" entre membros do governo e funcionários e proprietários das empresas de segurança, mecanismo por meio do qual ex-funcionários do governo saem para empresas privadas e ex-funcionários das empresas entram no governo, mantendo grande proximidade entre os dois círculos. Ou seja, esses três mecanismos garantem que as mesmas empresas mantenham ou renovem seus contratos, mesmo demonstrando ineficiência ou denúncias de violações e abusos. A crítica de Moore (idem) coloca mais ênfase na incapacidade do Estado, e não das próprias empresas, de fazer o mercado para a segurança funcionar de maneira adequada. Em resumo, de acordo com essa visão, o governo deveria assumir de maneira clara seu papel de consumidor quando se trata de serviços militares e substituir empresas caras, ineficientes ou que cometessem abusos. É claro que a autora não cogita a hipótese de que sejam exatamente estes alguns dos objetivos do mecanismo de privatização.

O ceticismo quanto à capacidade do mercado de apenas regular a atividade das PMSCs despertou, nas próprias empresas, uma necessidade de se diferenciarem, ou seja, criando dispositivos de autorregulação. A autorregulação é um desdobramento lógico da ideia de controle de mercado, pois significaria que as próprias empresas passariam a se preocupar com sua conduta e reputação. O primeiro marco desse movimento é a publicação de um artigo de Beese (2004), gerente administrativo da empresa inglesa ArmorGroup, defendendo que as empresas inglesas deveriam aderir voluntariamente aos instrumentos de controle construídos por elas mesmas. A ArmorGroup é uma companhia britânica, posteriormente adquirida pelo grupo G4S, que no ano da publicação de Beese já operava junto às forças da coalizão no Iraque. $\mathrm{O}$ artigo foi publicado, não por coincidência, no mesmo ano em que foram divulgadas as primeiras denúncias de abusos no tratamento de prisioneiros no Iraque. $\mathrm{O}$ artigo pretende demonstrar que um dos objetivos da regulação é diferenciar as PMSCs dos mercenários. Isso é, a segurança privada não têm nada em comum com as empresas privadas militares (PMCs) ou mercenários que se envolvem em suporte, operações de combate ofensivas que podem se aproveitar de suas operações e tentar mudar o equilíbrio de poder vigente em um país estrangeiro (idem).

O risco da perda de credibilidade fez com que as grandes empresas criassem uma série de associações comerciais ou industriais, que pudessem garantir códigos adequados de conduta, ou nas palavras de Hoppe e Quirico (2009), "responsabilidade social corporativa". Em 2006, a empresa inglesa Aegis, contratada pelo governo dos EUA para proteger as obras de reconstrução no Iraque, liderou a criação da British Association of Private Security Companies (BAPSC) (Richemond-Barak 2011, p. 1 063), responsável pela formulação de 
${ }^{7}$ Anteriormente chamada International Peace Operations Association (IPOA), mudou o nome para englobar também empresas que atuam em missões humanitárias.
${ }^{8}$ Para consultar o texto do artigo 47 do protocolo adicional da Convenção de Genebra sobre Mercenários, cf. United Nations (1979). um dos primeiros códigos de conduta para controlar as atividades das PMSCs, dentro e fora do Reino Unido. A criação da BAPSC fez com que o governo britânico postergasse a assinatura de nova legislação sobre PMSCs de maneira a privilegiar mecanismos privados de regulação. A maior das associações da indústria de segurança, a International Stability Operations Association (ISOA) ${ }^{7}$, fundada em 2001, foi concebida para servir exatamente como um selo de garantia para as empresas membro. A ISOA conta com um canal de reclamações que podem ser provenientes tanto de indivíduos quanto de empresas, dedicado a receber quaisquer denúncias de violação do código de conduta da associação (Isemberg 2011).

Apesar dessas diversas tentativas, a autorregulação avança muito pouco e tem reduzida capacidade de se impor, para além das mesmas limitações levantadas para a chamada "regulação de mercado". Embora as associações tenham conseguido formular códigos de conduta coletivos, as únicas consequências para violações seriam a expulsão das empresas denunciadas da própria associação, e a esperança de que os clientes dessa encerrassem seus contratos (Richemond-Barak 2011, p. 1 068). O mecanismo não é forte o suficiente para exercer qualquer tipo de controle mais efetivo, levando em consideração que, no máximo, $25 \%$ das empresas tem algum compromisso com quaisquer códigos de conduta, seja interno ou externo (idem, p. 1066 ).

Mesmo com grande esforço para viabilizar meios de regulação privados, aparece com cada vez mais clareza a necessidade de incluir algum tipo de regulação formal, seja dentro dos principais Estados, seja a partir de fontes internacionais. Durante os anos 1990 e início da década de 2000, a posição dos atores internacionais foi ambígua em relação às empresas. Enquanto a maioria dos Estados que se manifestaram sobre o assunto (incluindo Estados Unidos e Reino Unido) consideravam os funcionários das empresas como "contratados civis", (Cameron 2006, p. 574) o Conselho de Direitos Humanos da ONU estabeleceu, em 1997, um "Relator Especial sobre o uso de Mercenários", e o responsável pelo cargo até 2004, o peruano Enrique Bernales Ballesteros, manteve a posição de que os funcionários militares privados seriam mercenários e, portanto, deveriam ser objeto da Convenção de Genebra de 1949 e de seu protocolo sobre mercenários de 1977 (idem, p. 575).

No entanto, a definição de mercenário presente no Protocolo Adicional à Convenção de Genebra é vaga, e dificilmente possibilitaria o enquadramento dos funcionários de empresas privadas $^{8}$. Essa posição se modificou em 2005, quando o relator foi substituído pelo Grupo de Trabalho Sobre o Uso de Mercenários, que deveria, além de monitorar as atividades de mercenários, oferecer propostas de atualização das normas que regulam tais atividades, de maneira a preencher as lacunas existentes tanto nas legislações locais quanto nas leis internacionais. Como já mencionamos, essa transformação é consequência de uma percepção de que o fenômeno "veio para ficar", não podendo ser controlado apenas criminalizando a atividade das empresas privadas. Significou também uma vitória para as próprias empresas, que se esforçaram para se dissociar da imagem dos mercenários com os quais eram equiparadas.

A mudança dentro da ONU parece ter mais coerência com seu próprio modus operandi já que, desde os anos 1990, grande parte das operações da organização conta com o apoio das PMSCs. De acordo com Østensen (2011, p. 10) os contratos entre ONU e as empresas geralmente feitos de maneira ad hoc são bastante heterogêneos dentro dos diversos ramos do sistema ONU onde são empregados. A ONU emprega empresas dentro de três grandes linhas: missões humanitárias, missões de paz e missões políticas (idem, p. 11). Østensen destaca que os contratos são observados como "band-aids" para situações em que agências da ONU precisam operar em ambientes hostis (idem, p. 6), mas os 
gastos da organização com serviços terceirizados de segurança continuam se expandindo. Os gastos com serviços de segurança aumentou de US\$ 44 milhões em 2009 para US\$ 75 milhões em 2010 e US\$ 114 milhões em 2011 (DeWinter-Schmitt 2013, p. 141). Apesar da ONU ter um Grupo de Trabalho sobre o uso de mercenários, possui procedimentos vagos e pouco controle sobre seu próprio papel como cliente das empresas.

Devido à percepção generalizada a respeito do vazio jurídico no qual operam as empresas militares de segurança privada foi assinado, em 2008, o acordo chamado "Documento de Montreux". O documento foi formulado por iniciativa do governo da Suíça em parceria com o Comitê Internacional da Cruz Vermelha, em uma série de reuniões entre Estados, sociedade civil e representantes das PMSCs. O Documento de Montreux contou com a assinatura de 17 Estados, selecionados entre três grandes categorias, nos termos do acordo: (i) Estados territoriais, onde as empresas atuam, geralmente palcos de conflito; (ii) Estados de origem, onde as empresas estão sediadas e (iii) Estados contratantes, os grandes clientes das empresas. Dentro do grupo de Estados de origem, encontram-se Estados Unidos e Reino Unido que, não coincidentemente, são também dois grandes Estados contratantes. Entre os Estados territoriais se encontram Afeganistão e Iraque, entre outros. O documento contém uma série de obrigações legais e de "boas práticas" para os Estados signatários. As obrigações são, em geral, redundantes com as convenções de Direitos Humanos e das leis de guerra anteriormente assinadas. Já as "boas práticas” não passam de uma vasta carta de intenções, pois o documento não prevê nenhuma forma de punição a não ser as normas internas de cada Estado.

Em 2013 foi publicado o relatório "Montreux Five Years On”, iniciativa que tem por objetivo fiscalizar os esforços dos Estados signatários do Documento de Montreux passados os primeiros cinco anos (idem). As conclusões gerais foram de que os Estados signatários avançaram muito pouco em normas para contratação, monitoramento e prestação de contas sobre atividades e contratos de PMSCs, com destaque negativo para os Estados Unidos, o maior dos chamados "Estado de origem". Como já discutimos, ao mencionar os casos de violação ocorridos no Iraque por empresas norte-americanas, as leis dos EUA relativas à operação de agentes do Estado fora de seu território, além das limitações das legislações das unidades federativas, dificultam o avanço de mecanismos de controle. No que se refere ao Reino Unido, o segundo maior "Estado de origem", preferiu privilegiar a autorregulação, fato que, segundo o relatório, contribui para a dificuldade em criar mecanismos eficazes de controle e monitoramento (idem, p. 157). Ainda segundo o relatório, o governo do Iraque propôs legislação para o controle das PMSCs em 2008, mas ainda não conseguiu aprovar quaisquer mecanismos específicos que controlem a operação das empresas no país (idem, p. 158).

Um desdobramento do Documento de Montreux foi a assinatura, em 2010, do "International Code of Conduct for Private Security Service Providers" (ICOC), documento assinado por grandes empresas militares de segurança privada ${ }^{9}$ em acordo com o Código de Conduta para empresas militares de segurança privada formulado no Documento de Montreux. O chamado arranjo híbrido, já que foi formulado pelos Estados em conjunto com as empresas (Richemond-Barak 2011) é o primeiro compromisso internacional, de empresas de diversas partes, com normas de conduta que tenham sido formuladas por terceiros. O ICOC pode ser considerado um passo intermediário entre a chamada autorregulação, e uma tentativa dos Estados e da sociedade civil de controlar e regular as atividades de segurança privada.

Apesar de seu caráter inovador, o ICOC avança muito pouco na capacidade de controlar as atividades das empresas. Mais uma vez, o documento não passa 
de uma ampla declaração de boas intenções, já que deixa de estabelecer mecanismos de verificação independentes, a não ser relatórios como o "Montreux Five Years On" que, embora ofereça grande número de denúncias e recomendações, pouco pode fazer além de oferecer "conscientização". Além disso, boa parte das recomendações já faz parte das legislações específicas dos Estados, como violações por tráfico de pessoas e tortura, inclusive pelas quais algumas empresas signatárias do ICOC, como a Academi (antiga Blackwater) já foram processadas. Até o momento, embora as empresas tenham aderido a uma série de mecanismos de controle, voluntariamente ou não, as violações seguem ocorrendo sem que as empresas e seus funcionários sejam punidos, seja pelo mercado, pelas associações, pelas cortes locais, seja pelos organismos internacionais. Tudo leva a crer que os esforços de regulação servem, por enquanto, como cortina de fumaça para a continuidade das operações das empresas privadas que operam num terreno jurídico de imprecisões e indefinições conceituais.

\section{Conclusões}

Logo no início da chamada "guerra ao terror", analistas militares e policymakers norte-americanos empreenderam uma campanha no sentido de valorizar as experiências históricas dos EUA em operações militares, segundo eles frequentemente ignoradas pela maioria dos líderes políticos e chefes militares que sempre preferiam "glamouriar" as grandes guerras. O argumento é que se deveria aprender com as experiências bem sucedidas dos EUA nas pequenas guerras (small wars) para orientar suas ações no Iraque e Afeganistão (Boot 2003). De acordo com Boot (idem), o sucesso dos Estados Unidos na II Guerra Mundial fez com que se valorizasse uma única maneira de pensar a guerra, levando os oficiais norte-americanos a cultivarem uma grande aversão à luta em lugares difíceis (cidades, selvas e as montanhas) onde a distinção entre combatentes e civis é difícil de determinar. E o que se tornou mais prejudicial aos interesses estratégicos dos EUA, segundo essa crítica, corporificou-se em quatro grandes mitos: $(i)$ a ideia de que os EUA não devem entrar em nenhum conflito militar sem antes esboçar claramente qual é o seu "interesse nacional"; (ii) para entrar numa guerra os norte-americanos devem ter um significativo apoio popular; (iii) deve haver necessariamente uma declaração de guerra por parte do governo dos EUA; (iv) as tropas dos EUA sempre agiram como "trabalhadores sociais" e fizeram "deveres não convencionais" agindo como administradores coloniais (idem).

Para Boot (idem) o ideal seria que o Congresso autorizasse dimensionar o tamanho das Forças Armadas com os compromissos mundiais que se espera de uma grande potência. Mas o legislador, nos regimes democráticos, é sempre relutante em gastar o que se exige na área de defesa, além de ser mais relutante ainda em exigir recrutamento militar. De fato, as demandas sobre os EUA são tão numerosas e elásticas que mesmo que tivesse muito mais recursos, as exigências para uma intervenção seriam ainda maiores. Com isso, conclui Boot, essa parceria entre serviços públicos e privados, na área de segurança, é essencial e só tende a aumentar já que contorna os obstáculos mencionados acima.

Sem dúvida, observa Merom (2003), as democracias têm manifesta dificuldade em lidar com as pequenas guerras, principalmente porque as exigências morais e políticas vão muito além do que as regras democráticas domésticas, ou mesmo os princípios do Direito Internacional, estão dispostos a aceitar. Nessas guerras, as elites estabelecem uma oposição muito clara entre o que o governo entende que tem de fazer para vencer e aquilo que se considera politicamente aceitável dentro das normas universais de direitos humanos, bem como a 
sustentação da opinião pública. As democracias têm problemas em convencer a sociedade da necessidade de certos custos políticos e morais na contrainsurgência e, assim, uma parte da sociedade pode exercer forte pressão sobre o Estado com críticas sobre os custos morais e políticos a respeito da conduta das forças militares, estabelecendo uma competição entre a sociedade e o Estado. De outro lado, o Estado responde com manipulação e censura ameaçando as regras democráticas. A oposição pode chegar ao ponto de negar ao Estado a sustentação popular e o consenso nacional, necessários para utilizar todos os recursos disponíveis, já que sua superioridade militar é evidente (idem).

Como vimos, a presença de contratados privados permite que a responsabilidade de operações mal sucedidas, ou quando há violações de direitos humanos, incluindo torturas e assassinatos, seja atribuída a terceiros e não diretamente ao Estado. Além disso, a presença da grande quantidade de estrangeiros permite que se explore um vazio jurídico, já que os envolvidos não fazem parte das forças locais, nem das forças de coalização. Outra consequência da grande presença de terceirizados, principalmente estrangeiros, é o impacto notável na quantidade de baixas nas forças armadas norte-americanas. Um norte-americano contratado pelas empresas, não é considerado militar e, portanto, entra nas listas de civis mortos (mesmo que ele seja, de fato, um soldado privado). Já os estrangeiros de terceiros países não figuram nem mesmo nessas listas. No final das contas, são mortes denominadas de "invisíveis", sem nenhuma repercussão nos debates sobre a guerra. Segundo Avant (2010), desde o início da guerra no Iraque até o primeiro trimestre de 2007, para cada artigo que mencionava eventualmente as PMSCs no The New York Times, havia 47 artigos que tratavam das tropas militares.

A terceirização e a privatização, em vez de constituírem elementos de enfraquecimento do Estado, podem significar, na verdade, acesso a recursos que por quaisquer motivos lhe haviam sido retirados. É por meio das empresas privadas que o Estado pode operar em territórios que por motivos jurídicos seriam inacessíveis. Além disso, o processo de terceirização permitiu que o Estado norte-americano adotasse práticas e procedimentos que normalmente estão associados a violações dos direitos humanos, sem ter que arcar com os custos de tais violações (idem).

A grande maioria dos pesquisadores de PMSCs adota a perspectiva dos teóricos que entendem a globalização como um amplo processo de desregulamentação e de privatização que ocasionaram a retração do Estado. O problema dessa visão é que ela somente capta o retraimento do Estado na regulação da economia, mas não registra todas as maneiras em que o Estado participa ativamente, estabelecendo as novas estruturas que promovem a globalização, além de não captar as transformações correspondentes nas estrutura estatais. Na verdade, como observou Sassen (2010, p. 31), tratou-se muito mais de reestruturação e reordenação do Estado do que propriamente seu retraimento. O Estado tornou-se um dos polos centrais de uma rede de atores distribuídos em uma estrutura internacional extremamente complexa.

Entendemos que adotar essa perspectiva sobre o processo de privatização nos permitiu abordar o tema das PMSCs com um olhar distinto do que defende parte da literatura específica sobre o tema ${ }^{10}$, que considera as empresas militares de segurança privada o símbolo da perda de poder dos Estados e que, no limite, leva a uma naturalização do fenômeno, já que faz crer que os atores privados aparecem sempre como consequência e não necessariamente como parte integrante dos processos de privatização e desregulamentação. Entendemos que o crescimento da terceirização de serviços militares faz parte de um amplo reordenamento que tem, evidentemente, interessados e prejudicados em seu processo de implementação. Portanto, devemos identificar de que maneira as 
respostas do Estado, no sentido de descentralizar e terceirizar funções, que eram exclusivamente de sua alçada, podem ser compreendidas também em função de seus interesses, por exemplo, vislumbrando maior flexibilidade e menor necessidade de prestação de contas de empresas privadas (idem).

O número de empregados de terceiros (nem iraquianos, nem provenientes de algum dos países membros da coalizão liderada pelos Estados Unidos) empregados pelo Departamento de Defesa alcançou, em 2010, mais da metade dos contratados no Iraque. Em sua grande maioria são provenientes de países do sul da Ásia, do Leste Europeu, da América Latina e da África, bem treinados por seus exércitos nacionais e dispostos a trabalhar por salários muito mais baixos que os europeus ou norte-americanos em um ambiente de alto risco (Glanz \& Lehren 2010). Na primeira metade de 2010, pela primeira vez o número de mortes de contratados superou o número de baixas nas tropas americanas. Nesse período, o número de militares era aproximadamente de um para um entre os contratados privados pelo Departamento de Defesa, aproximadamente 90 mil homens (Schwartz 2010).

Embora não existam dados recentemente atualizados, é muito provável que esse índice tenha se desequilibrado em favor das forças privadas, já que o número de soldados norte-americanos foi reduzido após o anúncio da retirada, feito pelo presidente Barack Obama no final de agosto de 2010. No final de 2003, no começo do projeto de reconstrução, havia mais de 60 empresas americanas de segurança no Iraque e aproximadamente 25 mil empregados (Pelton 2006, p. 107). O resultado desse desequilíbrio é que a quantidade de baixas de tropas americanas foi drasticamente reduzida, sem que necessariamente fosse reduzida a presença norte-americana.

O crescimento da privatização da indústria militar reflete as demandas da estratégia norte-americana em contexto das guerras assimétricas. Uma série de medidas legislativas foram implementadas durante a guerra no Iraque afastando certas exigências constitucionais decorrentes de situações onde havia declaração de guerra, como por exemplo, autorização de contração de PMCs pelo Departamento de Defesa. A expansão no número de contratados e a ampliação dos papéis desempenhados pelas PMCs na Guerra do Iraque corresponde mais diretamente às iniciativas do poder Executivo em reduzir o tamanho do ativo militar ativo, transferindo as responsabilidades para um setor privado difuso e oculto com impactos consideráveis na percepção do público.

Portanto, as PMSCs são as principais responsáveis por gerar e fornecer todo e qualquer tido de informação para o Estado norte-americano. São, de fato, os olhos e ouvidos dos tomadores de decisão, com grande poder para moldar a maneira como são percebidas as ameaças mas, na medida em que usufruem de contratos confidenciais, acabam por escapar dos instrumentos de "accountability” do próprio Estado (Nguyen 2007). É evidente que, se por um lado esse tipo de serviço significa uma ameaça aos instrumentos democráticos, tanto por seus métodos de investigação, quanto por sua falta de transparência, por outro, permite que o governo se utilize de métodos que negam os mínimos fundamentos do Estado de Direito, como violação de correspondência e e-mails, sem que tenham de passar pelo escrutínio público. Tudo isso não deixa de revelar que o Estado norte-americano, ao adotar as PMSCs como o modo mais adequado de se vencer a guerra contra o terrorismo, está diante de uma enorme contradição, não apenas da democracia representativa em relação aos processos de accountability, mas fundamentalmente entre os princípios básicos de respeito aos direitos humanos e a realidade do campo de operações militares onde realmente se faz a guerra. 
Reginaldo Mattar Nasser (reginaldonasser@gmail.com) é Doutor em Ciências Sociais pela Pontifícia Universidade Católica de São Paulo (PUC-SP) e Professor do curso de Relações Internacionais da mesma universidade e do Programa de Pós-Graduação de Relações Internacionais San Tiago Dantas (Unesp, Unicamp e PUC-SP).

Tomaz Paoliello (tomazpaoliello@ gmail.com) é doutorando no Programa de Pós Graduação de Relações Internacionais San Tiago Dantas (Unesp, Unicamp, PUC/SP) e professor do curso de Relações Internacionais da PUC (SP).

\section{Referências}

Abrahamsen, R.; Williams, M.C. 2011.Security beyond the State: Private security in International Politics.Cambridge (UK):Cambridge University Press.

Apuzzo, M.; Goldman, A. 2011. Steve Stormoen, Former CIA Officer, Under Scrutiny in Abu Ghraib Prisoner Death. The World Post, 13 July. Disponível em: http://www.huffingtonpost.com/2011/07/13/steve-stormoen-former-cia-officer-abu-ghraib-death-_n_896810.html. Acesso em: 3 fev 2015.

Avant, D. 2005. The Market for Force: The consequences of privatizing security. Cambridge (UK): Cambridge University Press.

2010. Private Security and Democracy: Lessons from the US in Iraq. Security Studies, 19(2), pp. 230-265.

Beese, C. 2004. Regulation - an Armorgroup perspective (private security companies). Business \& Human Rights Resource Centre.

Bensahel, B.; Oliker, O.; Crane, K.; Brennan Jr., R.R.; Gregg, H.S.; Sullivan, T.; Rathmell, A. 2008. After Saddam: Prewar planning and the occupation of Iraq. Santa Monica: RAND Corporation.

Boot, M. 2003. TheSavage Wars of Peace: Small Wars and the Rise of American Power. New York: Basic Books.

Borger, J. 2004. US Military in Torture Scandal. The Guardian, 30 Apr. Disponível em: http://www.theguardian.com/media/2004/apr/30/television.internationalnews. Acesso em: 3 fev 2015.

Cameron, L. 2006. Private Military Companies: Their status under international humanitarian law and its impact on their regulation. International Review of the Red Cross, 88(863), pp. 573-598.

Chatterjee, P. 2006. Intelligence in Iraq: L-3 Supplies Spy Support. CorpWatch, 9 Aug. Disponível em: http://www.corpwatch.org/article.php?id = 13993. Acesso em: 3 fev 2015.

DeWinter-Schmitt, R. 2013. Montreux Five Years On: An Analysis of State Efforts to Implement Montreux Document Legal Obligations and Good Practices. Scotusblog, 11 May. Disponível em: http://www.scotusblog.com/2012/05/setback-for-abu-ghraib-contractors/.

Dobbins. J.; Jones, S.G.; Runkle, B.; Mohandas, S. 2009. Occupying Iraq: A history of the Coalition Provisional Authority. Santa Monica: RAND Corporation.

Dunigan, M. 2011. Victory for Hire: Private security companies' impact on military effectiveness. Stanford: Stanford University Press.

Feith, D.J. 2008. War and Decision: Inside the Pentagon at the Dawn of the War on Terrorism. New York: Harper.

Glanz, J.; Lehren, A. 2010. Growing Use of Contractors Added to War's Chaos in Iraq. The New York Times, 23 Oct.

Gowan, R.; Johntsone, I. 2007. New Challenges for Peacekeeping: Protection, Peacebuilding and the "War on Terror". Coping with Crisis. Working Paper Series. International Peace Academy.

Harris, G.T. 2006. The Era of Multilateral Occupation. Berkeley Journal of International Law, 24(1), pp. 1-79.

Hettena, S. 2005. Reports Detail Abu Ghraib Prision Death; Was It Torture? Associated Press, 17 Feb. Disponível em: http://www.nbcnews.com/id/6988054/\#.U8WHio1dWW4. Acesso em: 3 fev 2015.

Hoppe, C.; Quirico, O. 2009. Codes of Conduct for Private Military and Security Companies: the state of Self-regulation in the Industry. EUI Working Paper, 2009/28. European University Institute.

Isemberg, D. 2011. The Weaknesses of PMSC Self-Regulation. Huffington Post, 8 Feb. Disponível em: http://www.huffingtonpost.com/david-isenberg/the-weaknesses-of-pmsc-se_b_819262.html. Acesso em: 3 fev 2015.

Johnson, K. 2012. Shields of War: Defining Military Contractors' Liability for Torture. American University Law Review, 61(5), pp. $1417-1$ 431. Disponível em: http://digitalcommons.wcl.american.edu/cgi/viewcontent.cgi?article=1656\&context=aulr.

King, R. 2014. Ex-NSA Chief Details Snowden's Hiring at Agency, Booz Allen. The Wall Street Journal, 4 Feb. Disponível em: http://online.wsj.com/news/articles/SB10001424052702304626804579363651571199832. Acesso em: 3 fev 2015.

Kinsey, C. 2006. Corporate Soldiers and International Security: The rise of private military companies. New York: Routledge.

Krahmann, E.; Abzhaparova, A. 2010. The Regulation of Private Military and Security Services in the European Union: Current Policies and Future Options. AEL Working Paper. Disponível em: http://cadmus.eui.eu/bitstream/handle/1814/18295/AEL_2010_8.pdf?sequence=1. Acesso em: 3 fev 2015.

Leander, A. 2005. The Power to Construct International Security: On the Significance of Private Military Companies. Millennium, 33(3), pp. 803-825.

Mazzetti, M. 2010. U.S. Is Still Using Private Spy Ring, Despite Doubts. The New York Times, 15 May. 2011. Former Spy With Agenda Operates a Private C.I.A. The New York Times, 22 Nov.

Merom, G. 2003. How Democracies Lose Small Wars: State, Society, and the Failures of France in Algeria, Israel in Lebanon, and the United States in Vietnam. New York: Cambridge University Press. 
Moore, A. 2011. How Better Regulation Can Make Private Military Contractors Work. Adam Smith Institute, 11 July. Disponível em: http://www.adamsmith.org/research/think-pieces/how-better-regulation-can-make-private-military-contractors-work/. Acesso em: 3 fev 2015.

Nguyen, V. 2007. Current Trends in Intelligence Outsourcing Affect Work Force Stability. Signal Online, Dec.

Østensen, Å.G. 2011. UN Use of Private Military and Security Companies: Practices and Policies. SSR Paper, 3. DCAF.

Pelton, R. 2006. Licensed to Kill: Hired guns in the war on terror. New York: Three Rivers Press.

Percy, S. 2007. Mercenaries: Strong Norm, Weak Law. International Organization, 61(2), pp. 367-397.

Perry, D. 2012. Blackwater vs. bin Laden: The Private Sector's Role in American Counterterrorism. Comparative Strategy, 31, pp. 41-55.

Pincus, W. 2007. Contractors in Iraq Have Become U.S. Crutch. Washington Post, 20 Aug. Disponível em: http://www.washingtonpost.com/wp-dyn/content/article/2007/08/19/AR2007081901314.html. Acesso em: 3 fev 2015.

Richemond-Barak, D. 2011. Regulating War: A Taxonomy in Global Administrative Law. European Journal of International Law, 22(4), pp. 1 027-1 069.

Sassen, S. 2010. Sociologia da Globalização. Porto Alegre: Artmed.

Scahill, J. 2008. Blackwater: a ascensão do exército mercenário mais poderoso o mundo. São Paulo: Companhia das Letras.

Schreier, F.; Caparini, M. 2005. Privatizing Security: Law, Practice and Governance of Private Military and Security Companies. DCAF Occasional Paper, 6. Geneva Centre for the Democratic Control of Armed Forces.

Schwartz, M. 2010. Department of Defense Contractors in Iraq and Afghanistan: Background and Analysis. CRS Report for Congress. Congressional Research Service.

Shaw, M. 2005. The New Western Way of War. Cambridge (UK): Polity Press.

Shorrock, T. 2007. The Corporate Takeover of U.S. Intelligence. Salon, 1 June.

Singer, P.W. 2008. Corporate Warriors: The rise of the Privatized Military Industry. Ithaca: Cornell University Press.

Tonkin, H. 2011. State Control over Private Military and Security Companies in Armed Conflict. Cambridge (UK): Cambridge University Press.

Uesseler, R. 2008. Servants of War: Private military corporations and the profit of conflict. Brooklyn: Soft Skull Press.

White, J. 2005. Army, "CIA Agreed on 'Ghost' Prisoners". The Washington Post, 11 Mar. Disponível em: http://www.washingtonpost.com/wp-dyn/articles/A25239-2005Mar10.html. Acesso em: 3 fev 2015.

\section{Outras fontes}

Bloomberg. 2014. Company Overview of SpecTal, LLC. Disponível em: http://investing.businessweek.com/research/stocks/private/snapshot.asp?privcapId = 29017944

CIA officer may face war crime charges for unofficial interrogations at Abu Ghraib. 2011. Daily Mail, 13 July. Disponível em: http://www.dailymail.co.uk/news/article-2014319/CIA-officer-face-war-crime-charges-unofficial-interrogations-Abu-Ghraib.html\#ixzz37ZoXKf2S/. Acesso em: 3 fev 2015.

DCAF. 2006. Private Military Companies. DCAF Backgrounder. Disponível em: file:///C:/Users/Fernando/Downloads/bg_private-military-companies\%20(1).pdf. Acesso em: 2 fev 2015.

ICOC. 2013. The International Code of Conduct for Private Security Service Providers Signatory Companies. Disponível em: http://www.icoc-psp.org/uploads/Signatory_Companies_-_September_2013_-_Composite_List_SHORT_VERSION1.pdf. Acesso em: 3 fev 2015.

L-3 Communications' Government Services, Inc. Subsidiary Awarded Potential \$426.5 Million U.S. Army Intelligence Support Services Contract. 2005. Business Wire, 13 July. Disponível em: http://www.businesswire.com/news/home/20050713005224/en/L-3-Communications-Government-Services-Subsidiary-Awarded-Potential\#.U_F1q4BdWug. Acesso em: 3 fev 2015.

United Nations. 1979. Protocol Additional to the Geneva Conventions of 12 August 1949, and relating to the Protection of Victims of International Armed Conflicts (Protocol 1). Disponível em: http://www.un.org/arabic/preventgenocide/rwanda/text-images/Geneva_Protocol1.pdf. Acesso em: 3 fev 2015.

United States. Congressional Budget Office. 2008. Contractors' Support of U.S. Operations in Iraq. CBO Paper, 3 053, August. Disponível em: http://www.cbo.gov/sites/default/files/08-12-iraqcontractors.pdf. Acesso em: 3 fev 2015.

United States. Department of the Army. 2011. Operational Contract Support Planning and Management. Army Regulation 715-9. Washington, DC. Disponível em: http://armypubs.army.mil/epubs/pdf/r715_9.pdf. Acesso em: 2 fev 2015. 


\section{Abstract}

After the September 11 attacks, private agencies contracts with the CIA and its anti-terrorism activities were a major contributor to the expansion of the private security market in Iraq. This paper aims on relating the growing role of private actors in the counterterrorism strategy of the coalition led by the US in the context of the Iraq occupation. We understand that the lack of control on private security companies' activities became functional for the liberal democracies engaged in this kind of armed action. In other words, the response to a transforming operational environment where the "new wars" happen is one of the factors leading to the rise of the PMSCs. The fact that the weakest enemy can impact the national cohesion of the great powers, imposing significant political and economic costs on their opponents, demands waging war beyond the military operations on the battlefield. Our hypothesis is that the US, and the military coalition that led the Iraq invasion sought to manage political risks (legitimacy) and the risk of life (for combatants and civilians), considered beyond what the public opinion is willing to accept. The strategy is to transfer risks to new civil contractor organizations, less visible, so as to make it extremely hard to determine liability.

KEYWORDS: terrorism; private military companies; Iraq; intelligence services; USA.

License information: This is an open-access article distributed under the terms of the Creative Commons Attribution License, which permits unrestricted use, distribution, and reproduction in any medium, provided the original work is properly cited. 